\title{
Life-history traits in an evergreen Mediterranean oak respond differentially to previous experimental environments
}

\author{
José M. Rey Benayas, Bárbara Cuesta, Pedro Villar-Salvador and Pedro Jáuregui
}

\begin{abstract}
Rey Benayas, J. M., Cuesta, B., Villar-Salvador, P. and Jaúregui, P. 2008. Life-history traits in an evergreen Mediterranean oak respond differentially to previous experimental environments. - Web Ecol. 8: 74-83.
\end{abstract}

\begin{abstract}
Living organisms respond both to current and previous environments, which can have important consequences on population dynamics. However, there is little experimental evidence based on long-term field studies of the effects of previous environments on the performance of individuals. We tested the hypothesis that trees that establish under different environmental conditions perform differently under similar post-establishment conditions. We used the slow-growing, evergreen Mediterranean oak Quercus ilex subsp. rotundifolia as target species. We analyzed the effects of previous environments, competition effects and tradeoffs among life-history traits (survival, growth, and reproduction). We enhanced seedling establishment for three years by reducing abiotic environmental harshness by means of summer irrigation and artificial shading in 12 experimental plots, while four plots remained as controls. Then these treatments were interrupted for ten years. Seedlings under ameliorated environmental conditions survived and grew faster during early establishment. During the post-management period, previous treatments 1) did not have any effect on survival, 2) experienced a slower above-ground growth, 3) decreased root biomass as indicated from reflectivity of Ground Penetration Radar, 4) increased acorn production mostly through a greater canopy volume and 5) increased acorn production effort. The trees exhibited a combination of effects related to acclimation for coping with abiotic stress and effects of intra-specific competition. In accordance with our hypothesis, tree performance overall depended on previous environmental conditions, and the response was different for different life-history traits. We recommend early management because it increased plot cover, shortened the time to attain sexual maturity and increased the amount of acorn production. Plots such as those assessed in this study may act as sources of propagules in deforested agricultural landscapes thus aiding natural establishment of new plants.
\end{abstract}

J. M. Rey Benayas (josem.rey@uah.es), B. Cuesta and P. Villar-Salvador, Univ. de Alcalá, Dept de Ecología, ES-28871 Alcalá de Henares, Spain. - P. Jáuregui, Univ. de Alicante, Dept de Ciencias de la Tierra, ES-03080 Alicante, Spain.

While genotype determines the potential performance of an individual, the multiple environmental conditions experienced during development and growth shape the resulting phenotype. Thus, performance of organisms can be influenced by both current and previous environments (Bazzaz 1996, Reekie et al. 1997, Metcalfe and Monaghan
2001, Weinig and Delph 2001, Relyea 2002, Grether 2005). However, whereas many basic and applied studies have addressed the effects of the manipulation of the current environment on the performance of organisms (Valladares et al. 2002, Castro et al. 2004, Rey Benayas et al. 2005), there is little experimental evidence of the effects of

Accepted 2 June 2008

Copyright (C) EEF

ISSN 1399-1183 
previous environments on the future performance. This type of experiments is scarce in the scientific literature.

Life-history theory predicts the existence of tradeoffs among traits - particularly survival, growth and reproduction - that can have important long-term consequences on population dynamics (Sadras 1996, Silvertown and Dodd 1999, Obeso 2002, Gilbert et al. 2006, Yoshida 2006). Tradeoffs are usually more apparent when resources are limited (Obeso 2002), as occurs in Mediterranean ecosystems. To determine the mechanistic bases of the effects of previous environments, we analyzed the consistency of the response for different life-history traits and their tradeoffs.

Most studies with woody species have focused on tradeoffs between growth and reproduction at the shoot level (Newell 1991), and less frequently at the entire plant or stand levels (Despland and Houle 1997). Further, hardly any investigations of reproduction costs have studied how these vary with plant size (Bañuelos and Obeso 2004, Sakai et al. 2006). Resources for plant growth can be allocated to both belowground and aboveground tissues. Because root biomass of adults is difficult to estimate, most studies of tree species addressing belowground growth use young individuals either planted in pots or grown in the field (Reich et al. 1998, Canham et al. 1999).

We aim to analyse the responses of several life-history traits of the slow-growing, evergreen Mediterranean oak Quercus ilex subsp. rotundifolia (Fagaceae) to previous environments in experimental plots. Moreover, we analyse the existence of tradeoffs between survival, growth, reproduction and biomass allocation. Environmental harshness was mitigated for three years to favour seedling establishment. Reduction of light and water stress increased seedling survival and growth rate (Rey Benayas 1998). After three years management ceased and saplings grew for ten years under natural, more severe environmental conditions. Previous research highlighted that trees that established under less stressful environmental conditions attained sexual maturity earlier than trees in control plots (Rey Benayas and Camacho 2004). Due to differential survival and growth during the first three years, these plots represent a range of intra-specific competition intensities.

We tested the hypothesis that trees that established under different environmental conditions respond differently to homogenous post-establishment environmental conditions. There are two possible types of response to the positive effects provided by previous management: inertia, i.e. plants retained the ability to respond favorably to natural environmental harshness, or reaction, i.e. plants were less capable of facing later environmental harshness. We expected that the type of response would vary among life-history traits with tradeoffs between root versus aboveground growth, survival versus growth, and growth versus reproduction. Reproductive individuals, which were more abundant in previously managed plots (Rey Benayas and Camacho 2004), were expected to grow more slowly. We also expected that the conflict for the allocation of resources to growth and reproduction would be more intense in those plots that have allocated proportionally more resources to roots than to shoots because of the cost of root maintenance.

We considered two levels of analyses, the individual and the plot (aggregates of interacting individuals). Because observational approaches often cannot demonstrate causal relationships as they do not control for environmental effects (Reznick 1985), experimental approaches are essential to advance our understanding of how the interplay between previous and current environmental conditions influences tradeoffs among life-history traits. This research has important applications for the restoration of Mediterranean woodlands because $Q$. ilex is a widespread structural species that comprises most of the community biomass where it thrives. Thus, we expect to obtain useful insights for restoration of other woodlands in the world.

\section{Methods}

\section{Field experiment}

The study site was located in central Spain $\left(40^{\circ} 3^{\prime} \mathrm{N}\right.$, $4^{\circ} 24^{\prime} \mathrm{W}, 450 \mathrm{~m}$ a.s.l.) and has a typical Mediterranean continental climate. Total annual precipitation is $480 \mathrm{~mm}$ and mean annual temperature is $15^{\circ} \mathrm{C}$. We conducted the experiment on a 1-ha plot on previous cropland where a plantation of Q. ilex seedlings was established in 1993. During the first three years, seedlings were subjected to one of four treatments arising from the combination of summer irrigation (presence or absence) and artificial shading (presence or absence), with four replicates per combination. The 16 treatment plots were $10 \times 10 \mathrm{~m}$. They were planted with 50 one-year-old seedlings separated two $m$ from each other with a regular distribution, 800 seedlings in total. Seedlings were previously cultivated in a nursery from acorns that were collected in a nearby locality to minimize genetic variation (Rey Benayas 1998). High plantation density eventually resulted in intense competition within plots.

\section{Measurements}

Treatments were halted in 1996, after which trees experienced natural rainfall and light conditions. At that time sapling density was different among treatments (Fig. 1) and plants were pre-reproductive. The plots were revisited in 2002-2005 to evaluate further performance of the trees. No other woody plant species had established in the plots. We measured: 1) mortality, 2) the relative growth rate (RGR) in tree volume (height $\times$ crown projected area), which was calculated for the periods 1996-2004, 


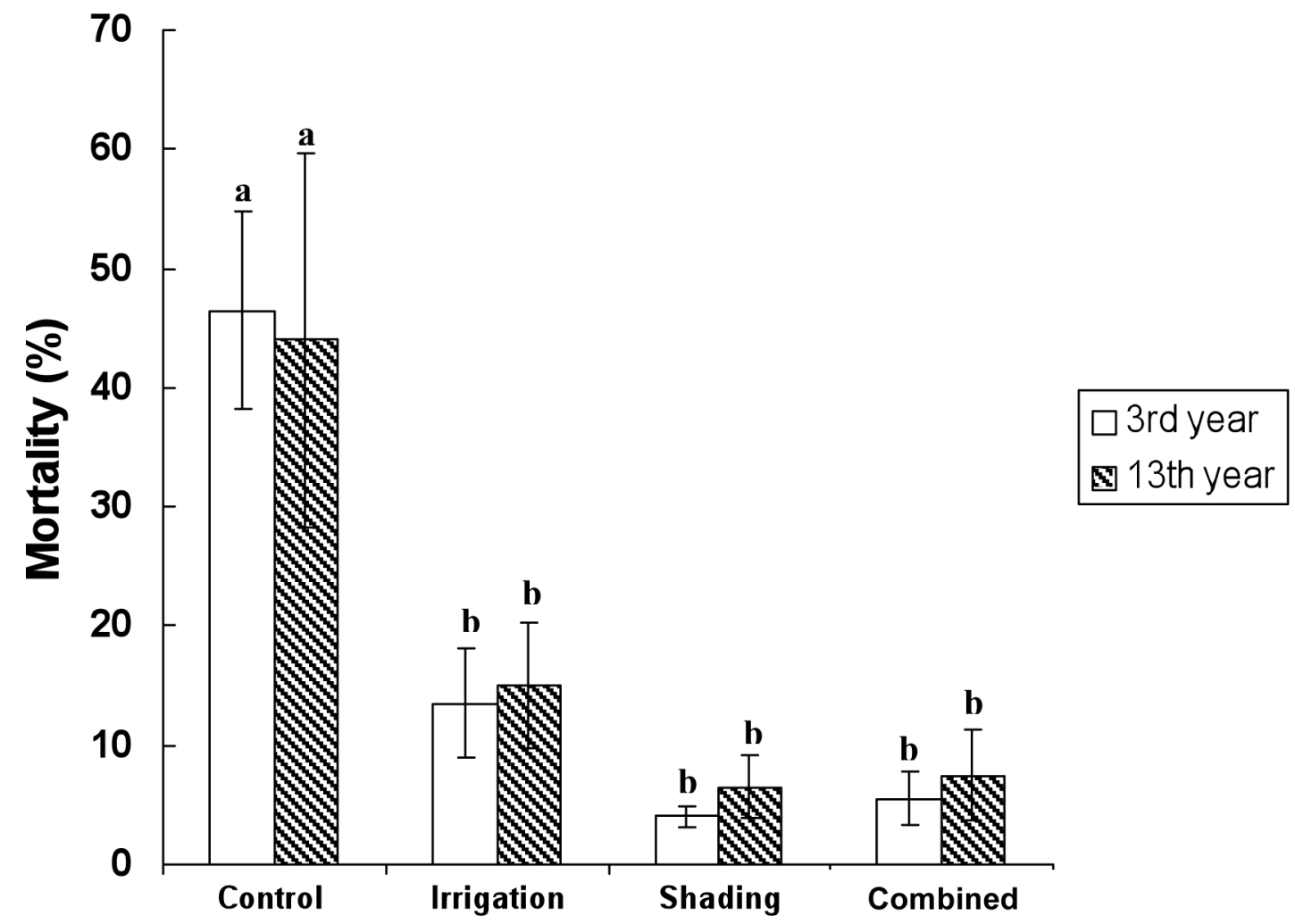

Fig. 1. Shaded bars: cumulative mortality of planted Q. ilex trees under different combinations of summer irrigation and artificial shading applied for three years and an additional ten-year post-treatment period $\left(\mathrm{F}_{3,11}=9.32, \mathrm{p}=0.0015, \mathrm{R}^{2}=68.9 \%\right)$. Open bars: mortality at the end of the treatment period reported by Rey Benayas (1998). Note: mortality counts during the entire 13-year period are lower than mortality counts during the first three years in control plots because resprouting of apparently dead saplings outweighed additional mortality. Different letters mean statistical differences within a year (3rd or 13th) at $\mathrm{p}=0.05$ according to a Tukey's test. Data are mean values \pm SE.

2002-2004 and 2004-2005, 3) canopy volume in a plot, i.e. the sum of the individual tree volumes, 4) plot ground reflectivity along a $2.2 \mathrm{~m}$ depth profile, a surrogate of plot root biomass, was measured using Ground Penetration Radar (GPR, $\lambda=16 \mathrm{~cm}$ ) (Antunes Aranha et al. 2002, Butnor et al. 2003). This estimates the volume of roots $2.5 \mathrm{~cm}$ in diameter or greater. The reflectivity in each plot was based on the signals of five $10 \mathrm{~m}$ tracks per plot and $\mathrm{ca}$ one radar pulse per $\mathrm{cm}$. To correct for ground signals other than roots, we measured the ground reflectivity in four adjacent herbaceous plots, and the average signal was subtracted from signal of the oak experimental plots. We note, though, that our reflectivity measures correspond to a fraction of the total roots. Ground reflectivity was not measured at the end of the management period, 5) shootto-root ratio in a plot was estimated as canopy volume/ ground reflectivity, 6) acorn production: all acorns were collected from all reproductive individuals in 2004, dried at $80^{\circ} \mathrm{C}$ for three days, and weighed. Acorn production effort of an individual was calculated as the ratio of acorn biomass and its canopy volume.

\section{Data analysis}

Our analytical unit was either the plot (stand level analysis) or the individual. At the plot level, we analyzed mortality rates, above- and belowground growth, and acorn production effort. We tested the tree response to previous environmental conditions and competition intensity by means of two-way ANCOVA (independent factors were irrigation and shading) and correlation analyses. Two measures were used as surrogates of competition intensity within a plot, tree density and canopy volume, which were marginally correlated $(\mathrm{r}=0.44, \mathrm{p}=0.091)$. Tree density ranged between 18 and 48 individuals per plot and canopy volume ranged between 50.1 and $342.6 \mathrm{~m}^{3}$ plot $^{-1}$ in 2005 . We expected that tree density and canopy volume of the plot would influence some life-history traits, e.g. effects of competition intensity on survival and growth and of tree size on fecundity. Therefore, canopy volume was used as a covariate in the ANCOVA models. We did not use tree density as a covariate in the ANCOVA models to avoid redundant hypothesis testing and results. To know if the 
Table 1. Results of the ANCOVA models used to test for the effects of previous environmental conditions (summer irrigation and artificial shading applied for three years) and canopy volume on several performance attributes of Quercus ilex trees during the postmanagement period. Error DF are 11.

\begin{tabular}{|c|c|c|c|c|c|c|c|c|c|c|c|}
\hline \multirow{2}{*}{ Source } & \multirow{2}{*}{ DF } & \multicolumn{2}{|c|}{ Mortality } & \multicolumn{2}{|c|}{ Volume RGR } & \multicolumn{2}{|c|}{ GPR reflectivity } & \multicolumn{2}{|c|}{$\begin{array}{l}\text { Shoot-to-root } \\
\text { ratio }\end{array}$} & \multicolumn{2}{|c|}{ Acorn production } \\
\hline & & $\mathrm{F}$ & $\mathrm{p}$ & $\mathrm{F}$ & $\mathrm{p}$ & $\mathrm{F}$ & $\mathrm{p}$ & $\mathrm{F}$ & $\mathrm{p}$ & $\mathrm{F}$ & $\mathrm{p}$ \\
\hline Summer irrigation & 1 & 1.14 & 0.31 & 4.79 & 0.051 & 2.43 & 0.15 & 0.70 & 0.42 & 1.6 & 0.23 \\
\hline Artificial shading & 1 & 0.18 & 0.68 & 80.59 & 0.000 & 7.37 & 0.02 & 8.14 & 0.016 & 2.93 & 0.11 \\
\hline Irrigation $\times$ shade & 1 & 0.98 & 0.34 & 8.52 & 0.014 & 3.53 & 0.09 & 4.90 & 0.04 & 5.60 & 0.038 \\
\hline Canopy volume & 1 & 1.20 & 0.29 & 4.74 & 0.052 & 0.06 & 0.81 & 263.0 & 0.000 & 107.40 & 0.000 \\
\hline Model ( $\left.\mathrm{R}^{2} \%\right)$ & 4 & $\begin{array}{l}0.54 \\
14 \%\end{array}$ & 0.71 & $\begin{array}{l}23.17 \\
85.5 \%\end{array}$ & 0.0000 & $\begin{array}{l}5.85 \\
49.7 \%\end{array}$ & 0.01 & $\begin{array}{l}128.1 \\
97.1 \%\end{array}$ & 0.000 & $\begin{array}{l}34.84 \\
90.0 \%\end{array}$ & 0.000 \\
\hline
\end{tabular}

conflict for the allocation of resources to growth and reproduction would be more intense in plots with contrasting shoot-to-root ratios (control and irrigation treatments), we used an ANCOVA (the categorical factor was the treatment, the covariate was acorn production effort) to test for parallelism between this ratio and the dependent variable (RGR). We used Tukey's tests for comparisons among treatments.
At the individual level, we looked at the tradeoff between aboveground growth and acorn production effort. Since the individuals were aggregated in plots, we tested the significance of the effect variables (sexual maturity, growth prior to the reproduction event, and growth subsequent to the reproduction event) in models with plot as a covariate random factor by means of GLM. First, we compared RGR between reproductive trees and non-

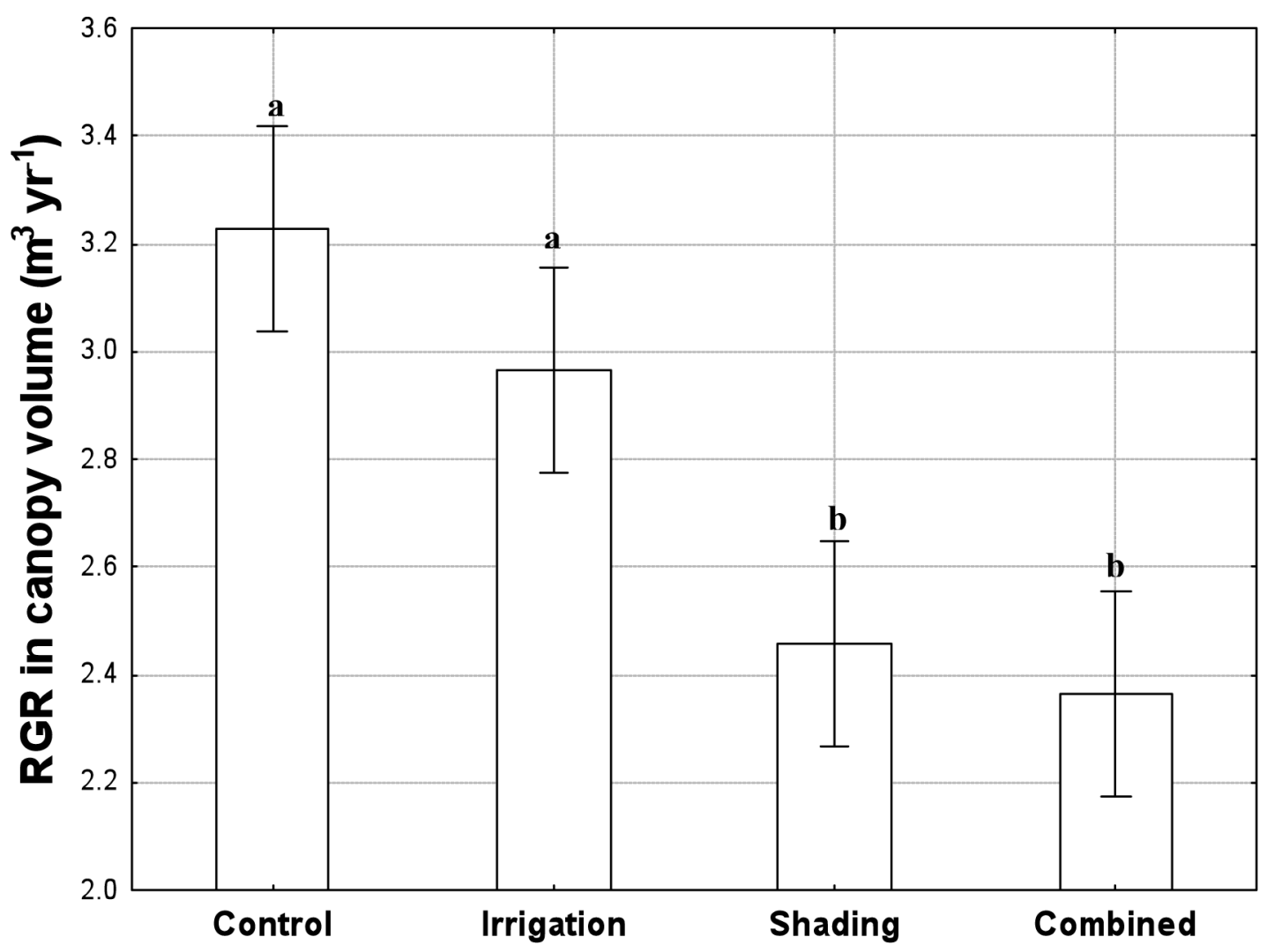

Fig. 2. Relative growth rate in canopy volume of planted $Q$. ilex trees during the post-treatment period after being previously treated by a combination of summer irrigation and artificial shading for three years. Different letters indicate statistical differences at $\mathrm{p}=0.05$ according to a Tukey's test. Bars denote $95 \%$ confidence intervals. 
reproductive trees. Next, the relationship between these traits was analysed by means of linear regression to relate the acorn production effort in 2004 with prior growth (2002-2004) and subsequent growth (2004-2005). We used Spearman's rank correlation instead of linear regression for cost of prior growth on reproduction because the residuals were not normally distributed due to high dispersion at low RGR values. All statistical analyses were performed with STATISTICA ver. 6.0.

\section{Results}

\section{Mortality and growth}

Treatments reduced mortality while they were applied, though mortality counts in control plots were highly variable (Fig. 1). Mortality among treatments during the postmanagement period ranged from $0 \%$ in control plots to $4 \%$ in shaded plots. These differences were not significant (Table 1) and were not related to competition intensity (Table 1; correlation between post-management mortality and density was $r=0.07, p=0.8$ ).

Previous management, particularly artificial shading and canopy volume caused a decrease in growth rate during the 1996-2004 post-management period (Table 1, Fig. 2). Relative growth rate was also negatively correlated with current plot tree density $(r=-0.76, p=0.0006)$. At the end of the experiment, irrigated plots had greater canopy volumes, but only in non-shaded conditions (irrigation $\times$ shade interaction $\mathrm{F}_{1,12}=5.85, \mathrm{p}=0.032$ ). However, the differences in canopy volume among treatments were small $\left(\mathrm{F}_{3,12}=2.47, \mathrm{p}=0.11\right)$. Post-management mortality and RGR were not correlated $(\mathrm{r}=-0.21, \mathrm{p}=0.44)$.

Ground reflectivity was higher in control plots than in previously managed plots (Table 1, Fig. 3a). It was not related to canopy volume but it was negatively correlated with tree density $(r=-0.65, p=0.006)$.

Previous management increased the shoot-to-root ratio at the end of the experiment (Table 1, Fig. 3b). Shoot-toroot ratio was positively related to plot density $(r=0.52$, $p$ $=0.04)$. During the entire post-management period and during the 2004-2005 period, RGR was not correlated with the shoot-to-root ratio $(\mathrm{r}=-0.1, \mathrm{p}=0.81$ and $\mathrm{r}=$ $-0.43, \mathrm{p}=0.096$, respectively).

\section{Growth and reproduction}

Acorn production in a plot depended on canopy volume and the irrigation and shading interaction (Table 1); more voluminous canopies produced more acorn biomass, and previous irrigation increased acorn production only in fulllight plots. Acorn production effort and the shoot to root ratio were positively correlated (Fig. 4). Relative growth a)

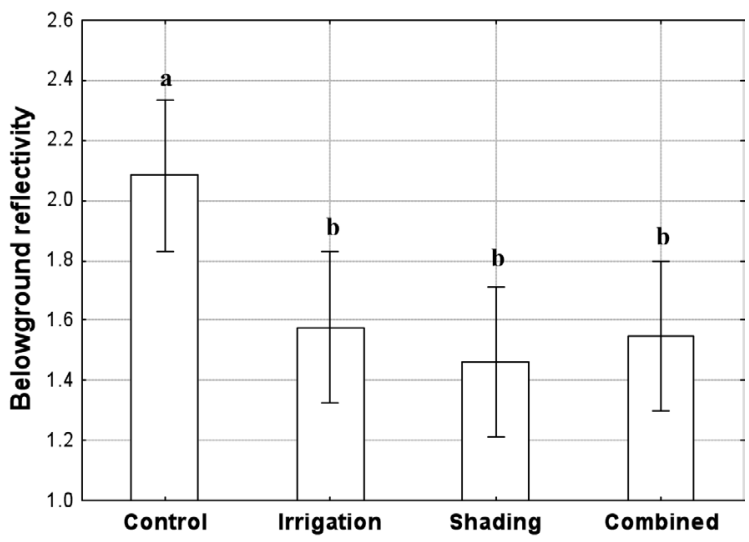

b)

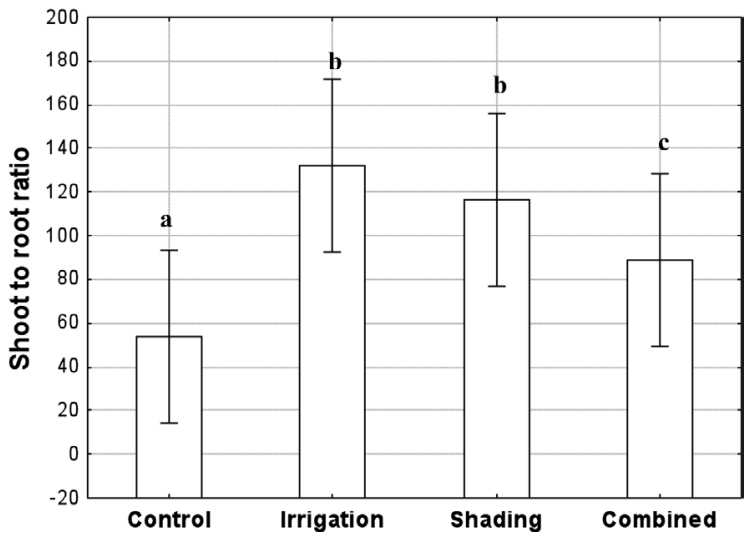

Fig. 3. Ground reflectivity (a) and shoot-to-root ratio (b) in plots of planted $Q$. ilex trees after 13 years having previously been treated by a combination of summer irrigation and artificial shading for the first three years. Different letters above the bars indicate statistical differences at $\mathrm{p}=0.05$ according to a Tukey's test. Bars denote $95 \%$ confidence intervals.

rate in the treatments with the most contrasting shoot to root ratios (i.e. control plots and irrigated plots) was not affected by the interaction between treatment and the acorn production effort $(p=0.37)$; this means that the slopes of RGR vs acorn production effort were similar in the contrasting plots.

GLM individual-based models including the plot as a random factor indicated significant effects of sexual maturity on growth $(p=0.001)$ and of previous growth on reproduction $(\mathrm{p}<0.0001)$, but not of reproduction on subsequent growth $(\mathrm{p}=0.37)$. Reproductive trees in $2004(\mathrm{n}=242)$ grew more slowly than non-reproductive trees $(\mathrm{n}=399)$ (mean 2004-2005 RGR \pm SD were 0.24 $\pm 0.22 \mathrm{~m}^{3} \mathrm{yr}^{-1}$ and $0.32 \pm 0.27 \mathrm{~m}^{3} \mathrm{yr}^{-1}$, respectively; $\mathrm{t}=$ 


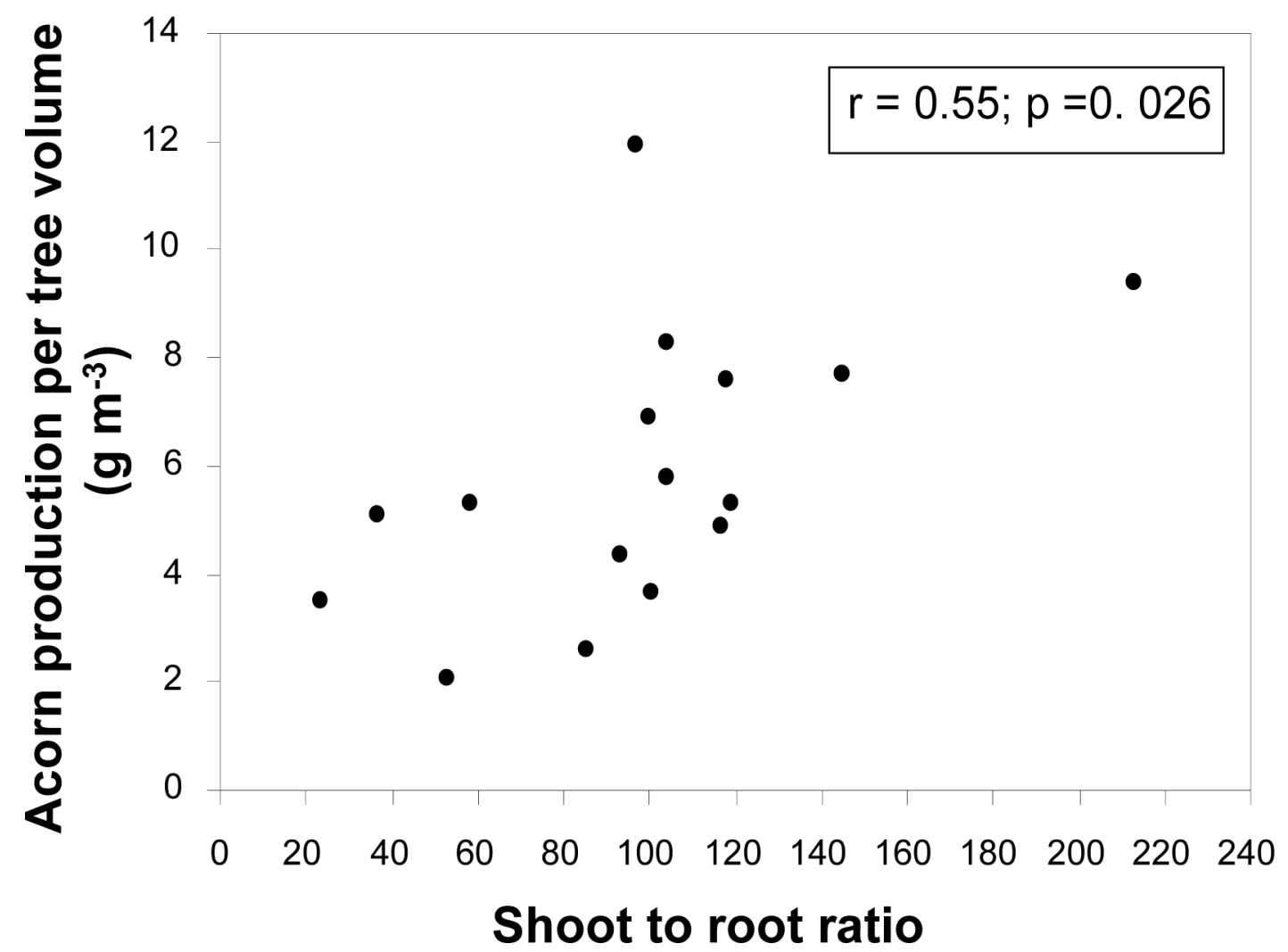

Fig. 4. Relationship between acorn production per canopy volume unit and shoot-to-root ratio $(\mathrm{n}=16)$.

$-4.24, \mathrm{p}<0.0001)$. The individual acorn production effort was negatively correlated with the growth in the previous two years (Fig. 5). This figure highlights low acorn production effort for high previous growth, whereas there is a range of acorn production effort for low to medium previous growth. Similarly, growth after the reproduction event (2004-2005) was negatively correlated with acorn production effort during $2004(\mathrm{r}=-0.15, \mathrm{p}=0.0003, \mathrm{n}$ $=583)$.

\section{Discussion}

\section{Tree response to previous environments}

Mitigation of stress due to high light and low water resulted in lower mortality and higher growth rate (Rey Benayas 1998). At that time, competition between saplings within a plot was negligible. In accordance to our hypothesis, trees that established under different environmental conditions overall responded differently to homogenous postestablishment environmental conditions, and the response was different for different life-history traits.
Previous environmental conditions did not affect subsequent mortality, an inertia response (Fig. 1). Many studies have demonstrated that the first year is critical for seedling establishment (Castro et al. 2004, Villar Salvador et al. 2004, Verdú and Traveset 2005). Under stressful conditions, survival usually follows a type-III or Weibull model, whereas under less stressful conditions survival follows a linear-hazard or type-II exponential model (Rey Benayas et al. 2005). There was little mortality in the post-establishment years after stress mitigation ceased. Low post-establishment mortality may be due to the development of deep roots that allowed trees to avoid drought and to aerial growth that made trees less sensitive to herb competition.

Post-management aerial growth was higher in control plots; the saplings that grew faster during establishment slowed down their growth later, a reaction ('pay later') response. This response was clear for previously shaded plots, and marginally significant for previously irrigated plots, coinciding with low mortality but little above-ground growth in established seedlings during the treatment period (Rey Benayas 1998). This result suggests that growth is a flexible trait regulated at optimal rates rather than at maximal rates (Edenius et al. 1993, Arendt 1997). We attribute the reduction in growth to a combination of different processes. 


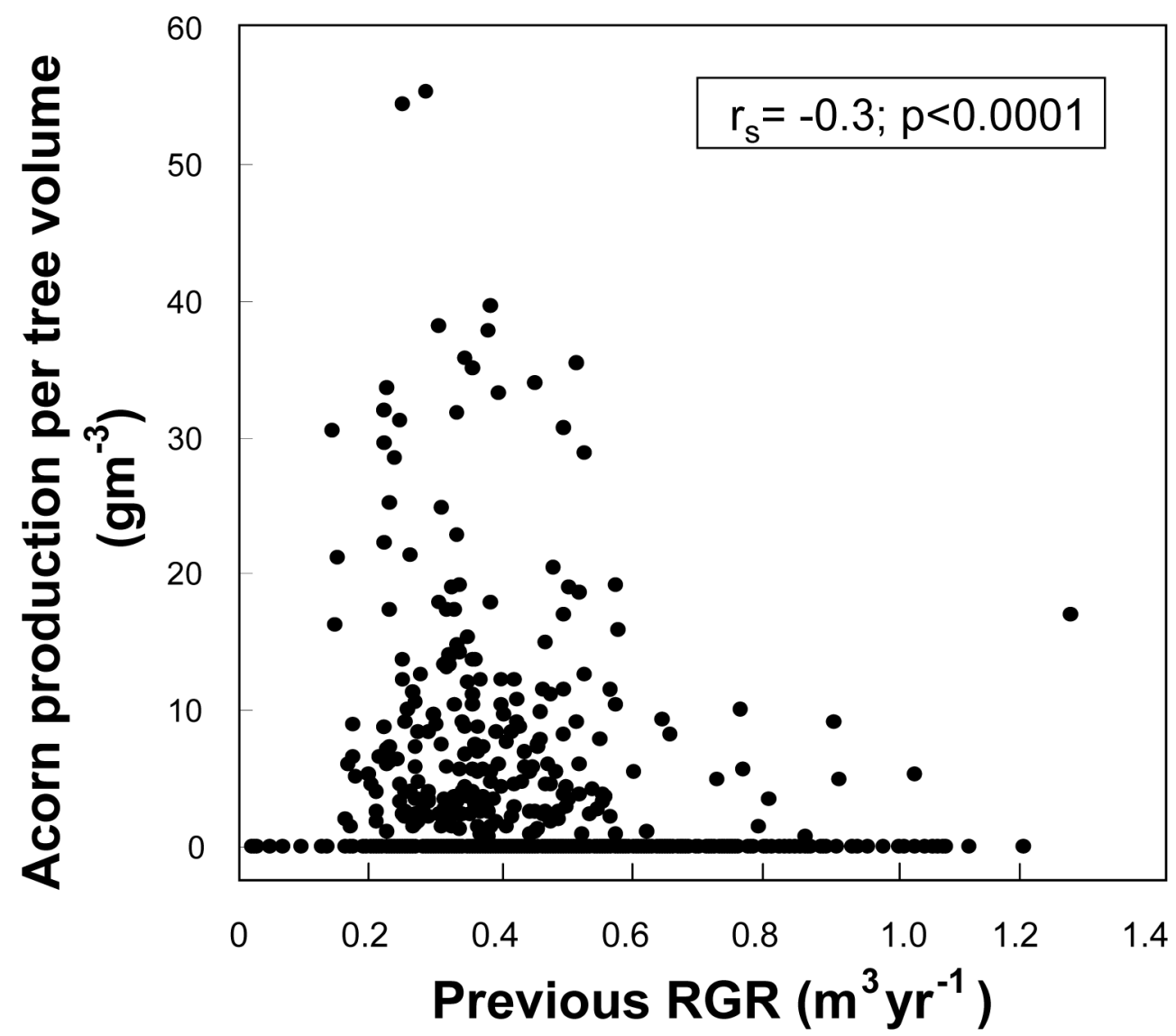

Fig. 5. Relationship between current acorn production per tree volume and previous relative growth rate in canopy volume (2002-2004) $(n=635)$.

First, plants grow more slowly as they become larger (van den Driessche 1992) because the proportion of photosynthetic tissues and the net assimilation rate declines with plant size (Walters et al. 1993). Secondly, there was higher intra-specific competition among trees in plots with previously ameliorated environmental conditions, as indicated by the negative relationships between RGR and canopy volume and density. Higher growth compensated for the high mortality due to abiotic stress in control plots; trees grew more at lower competition intensity than at higher competition intensity (Shabel and Peart 1994, Poorter et al. 2005). Third, after removing the effect of intra-specific competition, we still detected negative effects of previous management on growth, which may be a consequence of acclimation to cope with higher abiotic stress (photoinhibition, water shortage) after management interruption (Hikosaka et al. 2004). Fourth, previous management accelerated growth and trees in control plots achieved sexual maturity later (Rey Benayas and Camacho 2004). This experiment demonstrated that reproductive individuals grew more slowly than non-reproductive individuals. Fifth, there was a tradeoff between aboveground growth and reproduction.

\section{Tradeoffs between life-history traits}

Tradeoffs for resource allocation also explain the observed effects of previous environments. Root mass, as estimated by ground reflectivity, was higher in control plots in spite of the lower density. Root mass and canopy volume were not correlated, pointing to little competition for resources between roots and shoots (Willaume and Pages 2006). The differences among treatments in shoot to root ratio are explained only by root growth as little differences existed in canopy volume. The diversion of resources to root growth is a well-documented mechanism of plant adaptation to water stress that allows the use of resources more effectively (Chapin et al. 1993, Canham et al. 1996, Cornelissen et al. 1996, Sadras 1996). Allocation to roots also may be related to carbohydrate storage (Sadras 1996, Naidu and DeLucia 1997, Cherbuy et al. 2001, Drexhage and Colin 2001). However, a higher allocation of resources to roots can reduce RGR (Chapin 1990, Lambers and Poorter 1992, Antúnez et al. 2001). RGR and absolute growth in Q. ilex seedlings have been found to be positively correlated with the shoot to root ratio (Leiva and FernándezAlés 1998, Villar-Salvador et al. 2004). RGR and shoot to 
root ratio were not correlated in this particular experiment, suggesting that the growth and maintenance of roots did not impair aerial growth. A possible explanation is a better water status in plants with higher amount of root biomass that compensates for the costs of root maintenance (Leiva and Fernández-Alés 1998). In contrast, shoot-to-root ratio explained a significant amount of the variation in acorn production effort (Fig. 4). We interpret this result as a consequence of the high maintenance cost related to a low shoot to root ratio (Mooney 1972).

We found that non-reproductive trees grew faster than reproductive trees and that acorn production and growth was traded off. This suggests that vegetative and reproductive functions compete for common resources. The cost of prior growth on subsequent reproduction at the individual level was mostly a consequence of slow growth in plants with high reproductive investment (Fig. 5). These results are consistent with those of Newell (1991), Houle (2001), Obeso (2002) and Bañuelos and Obeso (2004) with other woody species. However, other authors have reported an absence of reproduction costs (Fox 1995, Despland and Houle 1997). Observational studies mostly report absence of tradeoffs or positive correlations between growth and reproduction, whereas manipulative studies highlight more easily the existing tradeoffs (Méndez pers. comm.).

Growth and survival during the post-management period were not related. Thus, growth did not have a density-dependent demographic cost yet. However, individuals grew more slowly in denser plots (Table 1, Fig. 2) or if they had a high acorn production effort (Fig. 5). This indicates that demographic costs (self-thinning) of early increased growth due to favored establishment and possibly of reproduction may appear soon, as it has been demonstrated for other tree species (Hoffman and Alliende 1984, Weiner 1990, Fox 1995, Sadras 1996, Silvertown and Dodd 1999).

\section{Application to plantation management}

Abandoned cropland and other deforested areas can be planted with native shrubs and trees to reduce soil erosion, increase biological diversity and create carbon sinks. However, the environmental conditions of these areas differ largely from those of the sites where natural regeneration of trees occurs (Rey Benayas et al. 2002), and the success of re-vegetation projects requires appropriate management. Since management is expensive, it is usually applied during a limited period after plantation takes place. Then, management is interrupted and the seedlings face a different environment than when they were first established.

Our results have important applications for tree species used for reforestation programs such as $Q$. ilex, an exemplary structural species in many forest communities of the central and western part of the Mediterranean basin. A benefit pursued by any restoration practitioner is to attain the highest re-vegetation cover in the shortest time. Consequently, we recommend early management because it increased plot cover (though this benefit was diluted with the age of plantation once management was halted), shortened the time to attain sexual maturity and increased the amount of acorn production. Plots such as those assessed in this study may act as sources of propagules in deforested agricultural landscapes thus aiding natural establishment of new plants (Chambers 2000, Robinson and Handel 2000, Rey Benayas et al. 2008).

To conclude, our results demonstrate that the current performance of organisms may be at least partially a consequence of previous environments. The interruption of the amelioration of environmental harshness during a threeyear establishment period did not have any effect on tree survival ten years later, decreased RGR, a response due to both previous treatments and competition effects, levelledoff canopy volume across treatment plots as a consequence of the combined inertia in mortality and reaction in aboveground growth, increased the shoot to root ratio through a diminished root growth, and lastly, increased acorn production effort whereas acorn biomass was tightly linked to tree size. We detected a tradeoff between growth and reproduction but not between these traits and survival and between above- and belowground growths. Long-term experiments under field conditions, like the one presented here, will be very valuable as a mean of optimizing resource investment in active restoration of woodland ecosystems of the world (Hooper et al. 2002).

Acknowledgments - This research has been financed by the projects CGL2004-00355/BOS, CGL2007-60533/BOS (Spanish Ministry of Science and Education) and S-0505/AMB/0355REMEDINAL (Madrid Government). We are indebted to our colleagues F. Maestre, M. Méndez, R. Obeso, F. I. Pugnaire and S. Scheiner for their friendly comments on a preliminary version of this manuscript.

\section{References}

Antúnes Aranha, P. R. et al. 2002. The use of GPR for characterizing underground weathered profiles in the sub-humid tropics. - J. Appl. Geophys. 49: 195-210.

Antúnez, I. et al. 2001. Relative growth rate in phylogenetically related deciduous and evergreen woody species. - Oecologia 128: $172-180$.

Arendt, J. D. 1997. Adaptive intrinsic growth rates: an interpretation across taxa. - Q. Rev. Biol. 72:149-177.

Bañuelos, M. J. and Obeso, J. R. 2004. Resource allocation in the dioecious shrub Rhamnus alpinus: the hidden costs of reproduction. - Evol. Ecol. Res. 6: 397-413.

Bazzaz, F. A. 1996. Plants in changing environments: linking physiological, population, and community ecology. - Cambridge Univ. Press.

Butnor, J. R. et al. 2003. Utility of Ground-Penetrating Radar as a root biomass survey tool in forest systems. - Soil Sci. Soc. Am. J. 67: 1607-1615. 
Canham, C. D. et al. 1996. Biomass allocation and multiple resource limitation in tree seedlings. - Can. J. For. Res. 26: 1521-1530.

Canham, C. D. et al. 1999. Interspecific and intraspecific variation in tree seedling survival: effects of allocation to roots versus carbohydrates reserves. - Oecologia 121: 1-11.

Castro, J. et al. 2004. Benefits of using shrubs as nurse plants for reforestation in Mediterranean mountains: a 4-year study. Rest. Ecol. 12: 352-358.

Chambers, J. C. 2000. Seed movements and seedling fates in disturbed sagebrush steppe ecosystems: implications for restoration. - Ecol. Appl. 10: 1400-1413.

Chapin III, F. S. 1990. The ecology and economics of storage in plants. - Ann. Rev. Ecol. Syst. 21: 423-447.

Chapin III, F. S. et al. 1993. Evolution of suites of traits in response to environmental stress. - Am. Nat. 142 (suppl.): 78-92.

Cherbuy, B. et al. 2001. Internal remobilization of carbohydrates, lipids, nitrogen and phosphorus in the Mediterranean evergreen oak Quercus ilex. - Tree Physiol. 21: 9-17.

Cornelissen, J. H. C. et al. 1996. Seedling growth, allocation and leaf attributes in a wide range of woody plant species and type. - J. Ecol. 84: 755-765.

Despland, E. and Houle, G. 1997. Climate influences on growth and reproduction of Pinus banksiana (Pinaceae) at the limit of the species distribution in eastern North America. - Am. J. Bot. 84: 928-937.

Drexhage, M. and Colin, F. 2001. Estimating root system biomass from breast-height diameters. - Forestry 74: 491-497.

Edenius, L. et al. 1993. Impact of herbivory and competition on compensatory growth in woody-plants - winter browsing by moose on Scots pine. - Oikos 66: 286-292.

Fox, J. F. 1995. Shoot demographic responses to manipulation of reproductive effort by bud removal in a willow. - Oikos 72: 283-287.

Gilbert, B. et al. 2006. Life history tradeoffs in tropical trees and lianas. - Ecology 87: 1281-1288.

Grether, G. F. 2005. Environmental change, phenotypic plasticity, and genetic compensation. - Am. Nat. 166: 115-123.

Hikosaka, K. et al. 2004. Photosynthetic rates and partitioning of absorbed light energy in photoinhibited leaves. - Physiol. Plantarum 121: 699-708.

Hooper, E. et al. 2002. Responses of 20 native tree species to reforestation strategies for abandoned farmland in Panama. - Ecol. Appl. 12: 1626-1641.

Houle, G. 2001. Reproductive costs are associated with both the male and the female functions in Alnus viridis ssp. crispa. Ecoscience 8: 220-229.

Hoffman, A. J. and Alliende, M. C. 1984. Interactions in the patterns of vegetative growth and reproduction in woody deciduous plants. - Oecologia 61: 109-114.

Lambers, H. and Poorter, H. 1992. Inherent variation in growth rate between higher plants: a search for physiological causes and ecological consequences. - Adv. Ecol. Res. 23: $187-261$.

Levia, M. J. and Fernández-Alés, R. 1998. Variability in seedling water status during drought within Quercus ilex subsp. ballota population, and its relation to seedling morphology. For. Ecol. Manage. 111: 147-156.

Mooney, H. A. 1972. The carbon balance of plants. - Ann. Rev. Ecol. Syst. 3: 315-346.
Metcalfe, N. and Monaghan, P. 2001. Compensation for a bad start: grow now, pay later? - Trends Ecol. Evol. 16: 254-260.

Naidu, S. L. and De Lucia E. H. 1997. Growth, allocation and water relations of shade-grown Quercus rubra L. saplings exposed to a late-season canopy gap. - Ann. Bot. 80: 335-344.

Newell, E. A. 1991. Direct and delayed costs of reproduction in Aesculus californica. - J. Ecol. 79: 365-378.

Obeso, J. R. 2002. The costs of reproduction in plants. - New Phytol. 155: 321-348.

Poorter, L. et al. 2005. A monocarpic tree species in a polycarpic world: how can Tachigali vasquezii maintain itself so successfully in a tropical rain forest community? - J. Ecol. 93: 268-278.

Reekie, E. et al. 1997. Tradeoffs between reproduction and growth influence time of reproduction in Oenothera biennis. - Can. J. Bot. 75: 1897-1902.

Reich, P. B. et al. 1998. Close association of RGR, leaf and root morphology, seed mass and shade tolerance in seedlings of nine boreal tree species grown in high and low light. - Funct. Ecol. 12: 327-338.

Relyea, R. A. 2002. Costs of phenotypic plasticity. - Am. Nat. 159: 272-282.

Rey Benayas, J. M. 1998. Growth and mortality in Quercus ilex L. seedlings after irrigation and artificial shading in Mediterranean set-aside agricultural lands. - Ann. For. Sci. 55: 801-807.

Rey Benayas, J. M. and Camacho, A. 2004. Performance of Quercus ilex saplings planted in abandoned Mediterranean cropland after long-term interruption of their management. - For. Ecol. Manage. 194: 223-233.

Rey Benayas, J. M. et al. 2002. Early establishment of planted Retama sphaerocarpa seedlings under different levels of light, water and weed competition. - Plant Ecol. 159: 201-209.

Rey Benayas, J. M. et al. 2005. Effects of artificial shading and weed mowing on reforestation of Mediterranean abandoned cropland with contrasting Quercus species. - For. Ecol. Manage. 212: 302-314.

Rey Benayas, J. M. et al. 2008. Creating woodland islets: a new approach to reconcile ecological restoration, conservation, and agricultural land use. - Fron. Ecol. Environ., in press, doi: $10.1890 / 070057$

Reznick, D. 1985. Costs of reproduction - an evaluation of the empirical evidence. - Oikos 44: 257-267.

Robinson, G. R. and Handel, S. N. 2000. Directing spatial patterns of recruitment during an experimental urban woodland reclamation. - Ecol. Appl. 10: 174-188.

Sadras, V. O. 1996. Cotton compensatory growth after loss of reproductive organs as affected by availability of resources and duration of recovery period. - Oecologia 106: 432-439.

Sakai, A. et al. 2006. Do sexual dimorphism in reproductive allocation and new shoot biomass increase with an increase of altitude? A case of the shrub willow Salix reinii (Salicaceae). - Am. J. Bot. 93: 988-992.

Shabel, A. B. and Peart, D. R. 1994. Effects of competition, herbivory and substrate disturbance on growth and size structure in pin cherry (Prunus pensylvanica L.) seedlings. - Oecologia 98: 150-158.

Silvertown, J. and Dodd, M. 1999. The demographic cost of reproduction and its consequences in balsam fir (Abies balsamea). - Am. Nat. 29: 321-332. 
Van den Driessche, R. 1992. Absolute and relative growth of Douglas-fir seedlings of different sizes. - Tree Physiol. 10: 141-152.

Valladares, F. et al. 2002. The greater seedling high-light tolerance of Quercus robur over Fagus sylvatica is linked to a greater physiological plasticity. - Trees 16: 395-403.

Verdú, M. and Traveset, A. 2005. Early emergence enhances plant fitness: A phylogenetically controlled meta-analysis. Ecology 86: 1385-1394.

Villar Salvador, P. et al. 2004. Nursery cultivation regimes, plant functional attributes, and field performance relationship in the Mediterranean oak Quercus ilex L. - For. Ecol. Manage. 196: 257-266.

Walters, M. B. et al. 1993. Relative growth rate in relation to physiological and morphological traits for northern hard- wood tree seedlings: species, light environment and ontogenetic considerations. - Oecologia 96: 219-231.

Weiner, J. 1990. Asymmetric competition in plant populations. - Trends Ecol. Evol. 5: 360-364.

Weinig, C. and Delph, L. F. 2001. Phenotypic plasticity early in life constrains developmental responses later. - Evolution 55: 930-936.

Willaume, M. and Pages, L. 2006. How periodic growth pattern and source/sink relations affect root growth in oak tree seedlings. - J. Exp. Bot. 57: 815-826.

Yoshida, T. 2006. Ecological stoichiometry and the shape of resource-based tradeoffs. - Oikos 112: 406-441. 